\title{
Atenea
}

Revista publicada por la Universidad de Concepción COMISIÓN DIRECTORA:

Enrique Molina, Samuel Zenteno A., Luis D. Cruz Ocampo, Salvador Gálvez y Abraham Valenzuela C. (Secretario). EDITOR Y AGENTE GENERAL: CARLOS JORGE NASCIMENTO

\begin{tabular}{lll}
\hline \hline AÑo I & DICIEMBRE 31 DE 1924 & NúM. 10 \\
\hline \hline
\end{tabular}

Enrique Molina

\section{La religión según Guyau}

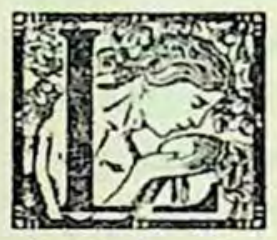

A obra dedicada por Guyau al estudio del problema religioso se halla animada de una tendencia práctica. Quiere probar que la disolución de las religiones positivas, ya iniciada desde el siglo XVIII. se consumaria en un futuro próximo. Esa tendencia se indica desde el título del libro: sLa Irreligión del Porvenir.

Sin embargo la primera parte está consagrada a teorias generales, al estudio del origen de las religiones en las sociedades primitivas.

- La idea de un lazo social entre el hombre y potencias superiores más o menos semejantes a él es para Guyau precisamente lo que hace la unidad de todas las concepciones religiosas.

La religión es un sociomorfismo universal: es una explicación fisica, metafisica y moral de todas las cosas por analogia con la sociedad humana bajo una forma imaginativa y simbólica. Por otra parte, en la religión se expresa la conciencia de nuestra dependencia ante poderes desconocidos y también nuestra necesidad de afección, de terneza, de amor.

Adelantando algo sobre las conclusiones de la obra podemos decir, desde luego. que, para nuestro filósofo, ser irreligioso o arreligioso no es lo mismo que antirreligioso. La irreligión del porvenir podrá conservar del sentimiento religioso lo que haya en él de más puro. como ser. por un lado. la admiración del cosmos y de las potencias infinitas que se han desplegado en él. y, por otro. la busca de un ideal no sólo individual sino social. y aún cosmico, que sobrepase a la realidad actual.

La irreligión de que hablamos debe ser considerada como un grado supe- 
rior de la civilización y de la religión misma. El desarrollo de la religión ha sido solidario con el de la civilización; esta ha comunicado a aquella mayor independencia de espiritu al frente del dogmatismo; la ha libertado de lo literal y estrecho y la ha hecho aceptar especulaciones más amplias.

En el proceso religioso la independencia del juicio individual ha sido la fuerza que ha socavado y minado los cimientos de las religiones. Ha sido la potencia que ha servido para levantar en el decurso histórico nuevas religiones en lugar de las anteriores que se derrumbaran una vez agotado su vigor espiritual. Esta misma fuerza traerá, según Guyau, la descomposición gradual de todo sistema de creencias dogmáticas.

Algunos prolesan. sin embargo, la idea de unificación efectuada en la que llaman sreligión del porvenir, sea judaismo perfeccionado, sea cristianismo perfeccionado. sea budismo perfeccionado. Antes que en esta sunidad religiosa. del porvenir nosotros creemos más bien, dice Guyau, en la pluralidad futura de las creencias, en la anomia religiosa. La anomia la consideramos el ideal humano y ella no excluye de ninguna manera las asociaciones progresivas y libres de los espiritus dentro de las hipótesis más generales, como lampoco excluye la conservación de lo mejor de la vida religiosa, de lo que hay en ella de intensidad sentimental y de amplitud espiritual.

Guyau analiza el argumento tan recorrido en favor de las creencias religiosas de que el pueblo, el niño y la mujer no pueden, sin peligro prescindir de ellas.

Con qué fina ironía se burla nuestro filósolo de los sabios que afirman que la religión es imprescindible al pueblo, sin perjuicio de que la consideren absurda para ellos mismos. Prolesan hacia el pueblo esta caridad un poco despreciativa de querer dejarlo tranquilo en sus falsas creencias, hundido en sus prejuicios como en el solo medio en que le convenga vivir. Según ellos, cierlos espíritus superiores pueden, sin inconvenientes, independizarse de la religión: la masa no lo puede. Sería menester reservar para una elife el libre examen y el libre pensamiento: la aristocracia del espiritu debe mantenerse en un campo cerrado. Así como - pan y circo, eran indispensables al pueblo romano. los pueblos modernos nece. sitan templos y es esta a veces la única manera de hacerles olvidar que no tienen bastante pan.

No cree Guyau tampoco que sea indispensable la religión ni para la educación del niño ni para la vida de la mujer. La considera aún peligrosa.

- La educación religiosa dada a los niños por el sacerdote, dice, tiene defeclos y aún peligros que importa señalar y que explican el debilitamiento gradual que va sufriendo. Una opinión divinizada es condenable lanto desde el punto de vista pedagógico como del cientifico. La gran oposición que existe entre la religión y la filosofia. a pesar de sus semejanzas exteriores, es que la una busca y la otra declara haber encontrado: mientras una presta el oido. la otra ha escuchado ya: mientras una ensaya pruebas. la otra formula afirmaciones y condenaciones; mientras una cree de su deber ponerse objeciones y responder a ellas. la otra se siente obligada a no detener su espiritu en las objeciones y a cerrar los ojos a las dificultades. De aquí se siguen profundas diferencias en los métodos 
de enseñanza. El filósolo pretende obrar sobre los espiritus por medio de la convicción; el sacerdote por la inculcación; uno enseña. el otro revela; uno trata de dirigir el razonamiento. el otro no quiere sino suprimirlo. o por lo menos apartarlo de los dogmas primitivos y fundamentales: uno derpierta la inteligencia, el otro tiende a adormecerla más o menos. ¿Cómo no ha de oponerse la revelación a la espontaneidad y libertad del espiritu? Cuando Dios ha hablado el hombre debe callarse y con mayor razón el niño. De esta suerte. los errores a menudo inofensivos si los enseña un filósolo. se tornan graves y peligrosos si es un sacer. dote hablando en nombre de Dios quien los introduce en el espíritu. Con el primero siempre se encuentra el remedio al lado del mal; lo que un razonamiento más o menos bueno os ha hecho admitir otro mejor puede haceros rechazarlo: teneis en vuestras manos los pesos y las medidas. No es siempre fácil demostrar y enseñar el error por medio de razones y razonamientos: tratar de fundar en la razón un prejuicio es un medio seguro para hacer estallar su falsedad. Siempre que la humanidad ha querido probarse a si misma sus creencias ha empezado a disolverlas: quien desea verificar un dogma se halla muy cerca de contradecirlo. Así el sacerdote. para quien la contradicción es una falta de le. se ve siempre obligado por la fuerza misma de las cosas a evitar la verificación. a prohibir un cierto número de cuestiones, a fortificarse en el misterio.

-Entorpecimiento de la libertad. ahogamiento del pensar. espiritu de rutina. de tradición ciega, de obediencia pasiva, en una palabra todo lo que es contrario al espiritu mismo de la ciencia moderna, tales son los resultados de una educación demasiado exclusivamente clericalı.

¿Y qué cabe decir de la mujer sobre el particular?

Las mujeres. se afirma, tienen el espíritu menos apto para la abstracción que los hombres: más gusto por lo que deslumbra los sentidos y la imaginación. por lo vistoso y coloreado: de aquí su necesidad de los mitos, de los símbolos. del culto. de los ritos que hablan a los ojos. Nosotros dudamos de que estas inclinaciones denoten caracteres femeninos lundamentales. ¿No se contentan las mujeres protestantes con un culto sobrio que no habla a los sentidos? Por otra parte un espiritu imaginativo no es forzosamente un espiritu supersticioso. He conocido. dice Guyau. muchas mujeres que no tenian ni una sola superstición y que eran incapaces de adquirirlas. En este respecto nada distinguia a su inteligencia de la inteligencia viril.

Se insiste en un segundo razgo de la inteligencia femenina, cual sería su necesidad de creer, que la inclinaría fácilmente a la fe religiosa.

Ciertamente es esta una necesidad que se observa más ostensiblemente en la mujer que en el hombre: pero ¿será ello el resultado de una condición esencial de la naturaleza femenina o simplemente de la educación que, por lo general. se ha dado hasta ahora a la mujer? Por lo demás. esta necesidad de creer que se supone en el sexo débil no es superior a las leyes según las cuales se moldean las creencias de los seres humanos. Lo que se crea o no se crea depende en definitiva de la acción de la familia, de la educación y de las sugestiones de las personas queridas y del ambiente en que se crece. 
Preguntaba, dice nuestro filósofo, a una criada que había permanecido treinta años en una misma casa, cuáles eran sus creencias. - Las de mi señorito. respondió.-Su reñorito era ateo. Se le hizo la misma pregunta a la señora de un miembro del Instituto. - Al casarme yo era católica, repuso, pero pronto pude apreciar la superioridad de espíritu de mi marido, vi que no creía en la religión y dejé yo misma de creer.

Un tercer razgo del espíritu femenino seria su espiritu conservador.

- El espiritu conservador, dice Guyau, puede aplicarse tanto a la verdad como al error, todo dependerá de lo que se le dé a conservar. Si se la instruye en conocimientos ciertos en el orden filosófico, cientifico. moral y práctico. su alma se alzará sobre una base de certidumbres y conservará certidumbres. Si se la instruye en supersticiones, conservará supersticiones. Es más o menos lo mismo que con otros términos acabamos de decir sobre el poder de la educación y de la sugestión.

Se hace también mucho caudal del poder del sentimiento en la mujer para valorizar sus predilecciones religiosas, como si se tratara por este motivo de esferas dificiles de comprender para el hombre. Pero en verdad no constituye un privilegio de las religiones el cultivo de los sentimientos ni es una recomendación para ellas que obren sobre los creyentes principalmente moviendo las cuerdas de la sensibilidad y no proyectando la luz de conceptos claros y coherentes. Se afirmaria en realidad con lo dicho el predominio en la mujer de una actividad o receptividad emotiva sobre la actividad intelectiva.

Por otra parte ¿cómo desconocer el lugar que el sentimiento ocupa en el hombre? ¿o será menester dejar sometida su capacidad de sentir a la condición de su religiosidad? ¿No hay entre los hombres indiferentes o arreligiosos muchos de nobles y puros sentimientos? Los más grandes misticos, dice Guyau, no han sido mujeres. Las Santas Teresas han sido menos numerosas que los Plotinos. los Jámblicos, los Dionisios Areopagitas, los Gerson, los Tauler y tantos otros.

Ha sido sin duda pobre defensa y pobre destino señalado a la religión considerarla indispensable sólo para los niños, para el pueblo i para las mujeres. Los hombres superiores podrian prescindir de ella. pero no los espiritualmente débiles. Presentada así seria una cosa buena. una engañifa necesaria para los intelectualmente inferiores. para retrasados mentales. Fuera del escaso favor que con esto se hace a las mujeres y al pueblo. en esta forma la religión distaria mucho de inspirarnos respeto. Es respetable sólo hecha fe viva en el pecho del creyente sincero que la abriga como un valor absoluto y primordial para todos los humanos sin distingos oportunistas de político esceptico.

En el estudio del problema religioso observamos en Guyau algo semejante a lo que hemos podido notar en sus especulaciones sobre la moral. Claro y decidido en la crítica de las ideas que estima inaceptables se torna flotante y confuso al ensayar la exposición de sus convicciones propias.

Completando lo que ya hemos indicado al empezar estas páginas vuelve nuestro filósolo al final de su obra sobre la cuestión de si será posible que al periodo por que atravesamos de disolución de las religiones se siga una renova- 
ción religiosa o de si alguna doctrina filosófica se muestre capaz de sustituir a las religiones. Ya sabemos que no se presenta como concebible que se refundan en una sola las religiones existentes, verbi-gracia, el catolicismo y el budismo, ni tampoco se divisa qué religión nueva pudiera arrastrar a la humanidad unida tras la consecución de un nuevo ideal. Parecen haber pasado los tiemqos de los mesias y de los profetas. La religión positivista no merece para Guyau los honores de una religión. La considera tan sólo como una estrecha idolatría fetiquista. Un tiempo se pensó que el socialismo pudiera llegar a ser la esperada religión universal: pero sus aspiraciones de carácter primordialmente económico le niegan loda posibilidad de convertirse en una verdadera religión del porvenir.

No se divisaria, pues, por delante nada más que el individualismo religioso. lá anomia religiosa. una libre diversidad en materia de creencias. situación en que, en lugar de aceptar dogmas enteramente hechos, debemos ser nosotros mismos los obreros de nuestras representaciones del más allá.

No obstante lo anterior, hace largas digresiones Guyau sobre qué hipótesis metafisicas podrian reemplazar a los dogmas. lo que equivale a ponerle término a la anomia recientemente anunciada como inevitable.

De dichas hipótesis examina Guyau primeramente el deismo en su aspecto más característico: la existencia de un dios creador y de una providencia. ¿La creación? Es una idea que se deriva de premisas falsas. La creación supone un principio $\sin$ movimiento y sin nada. Esto es el no ser y el no ser es más inconcebible que el ser. Por otra parte un dios creador que ha tenido a su disposición la eternidad para hacer el mundo y lo ha hecho tal como lo vemos revelaría ser un dios muy incapaz: la existencia del mal en la tierra es incompatible con la suposición de un dios creador omnipotente.

Tampoco es aceptable la idea de una providencia que haga irrupción contra las leyes naturales. Guyau no admite otra providencia que la de la acción humana guiada por la ciencia.

En seguida le loca su turno al panteísmo que Guyau lo divide en panteismo optimista y pesimista. Llama panteísmo optimista a la doctrina de Spinoza. Nuestro filósofo la analiza con complacencia; pero no la halla libre de reparos sin los cuales pudiera llegar a ser la religión del porvenir.

Se explica también nuestro filósolo el pesimismo sustentado por Schopenhauer y Hartmann; pero no lo justifica. Es tan contrario a su temperamento. Rastrea sus causas y va a buscar en ellas mismas el remedio del mal.

El pesimismo habria provenido sobretodo de una especie de fatiga intelectual de las generaciones de la pasada centuria. El saber humano que abruma actualmente el cerebro, dice Guyau, puede. organizándose mejor, tal como ya se encuentra en algunas cabezas bien equilibradas. producir algún día un sentimiento de bienestar y de vida más amplia. Hay que crear una ciencia nueva. la de la higiene intelectual para los pueblos y la de la terapéutica intelectual para los individuos.

-En cuanto a la reflexión de la conciencia sobre sí misma en que los pesimistas ven una fuerza disolvente de todas nuestras alegrías, ella no disuelve 
en verdad nada más que las alegrias irracionales, y por compensación, disuelve además las penas irracionales... El gran remedio contra el análisis llevado al extremo. según lo han practicado algunos espíritus del género de Amiel. siempre en contemplación de si mismo, consiste en olvidarse un poco de la propia personalidad. en ensanchar su horizonte, sobre todo en obrar. La acción es por su naturaleza una sintesis realizada, una decisión que resuelve un conjunto de puntos. Los resuelve sin duda provisoriamente; pero el hombre debe acordarse de que vive en lo provisorio. no en lo eterno: que. por lo demás. lo que hay de más eterno en este universo es talvez la acción misma. el movimiento. la vibración del átomo y la ondulación que atraviesa al gran Todo. El que obra no tiene tiempo para compadecerse de su caro yo ni para disecar sus sentimientos. El remedio a todos los sufrimientos del cerebro moderno se encuentra en henchir el corazóns.

Es falso también, como afirman los pesimistas. que las cosas se repitan y no ofrezcan más perspectiva que la de uua monotonia desconsoladora. La vida es como una ascención perpetua en que es muy dificil exclamar sYo lo he visto todo porque he trepado a la primera cima. De la infancia a la ancianidad el horizonte puede siempre renovarse. La naturaleza no parece copiarse sino para las miradas superficiales. Cada una de sus obras es original como las del genio. Tanto del punto de vista estético como del intelectual el desaliento es. pues, una ceguera....

En conclusión tampoco le parece a Guyau que el panteismo pesimista pueda ser la religión del porvenir.

Pasa después a estudiar el naturalismo materialista y el naturalismo idealista. que rechaza igualmente. En cambio el naturalismo monista cuenta con toda su adhesión.

.El verdadero monismo. dice, no es ni trascendente ni místico, es inmanente y naturalista. El mundo es un solo y mismo devenir: no hay dos naturalezas de existencia, ni dos evoluciones. sino una sola, cuya historia es la historia misma del universo.

En lugar de tratar de refundir la materia en el espiritu o el espiritu en la materia. tomamos a los dos reunidos en esta sintesis que la ciencia misma. extraña a todo prejuicio moral o religioso. se ve obligada a reconocer: la vida. La vida por su evolución misma tiende a engendrar la conciencia: el progreso de la vida se confunde con el progreso de la conciencia y es posible que haya asomos de conciencia hasta en el más rudimentario de los seres.

Al propio tiemqo que la vida tiende a tomar posesión de si misma por la conciencia, trata de difundirse por la acción, por una acción cada vez más invasora. La vida es no sólo nutrición sino fecundidad y producción. Así el egoísmo puro, en lugar de ser un engrandecimiento, significaría disminución y mutilación de sí mismo. De esta suerte, la individualidad, por su expansión. tiende a devenir sociabilidad y moralidad. Esta sociabilidad es la que, después de haber conformado el fondo del instinto moral, crea el instinto religioso o metafísico en lo que 
tiene de más profundo y más durable. La especulación metafísica. como la acción moral, queda ligada de esta suerte a la fuente misma de la vida.

Dentro de esta doctrina no cabria hablar de una evolución que tuviera una finalidad, que fuera providencial en una palabra: pero nos es dado en cambio concebirla como llegando a la producción de seres capaces de darse ellos un objeto a sí mismos y de llegar hacia él arrastrando a su zaga a las fuerzas de la naturaleza. La selección natural se cambiaria asi finalmente en una selección moral, y, en cierto sentido divina. Es esta sin duda, dice Guyau, una hipótesis bastante atrevida, pero que se haya sin embargo en la dirección de las hipótesis cientificas. Nada la contradice formalmente en el estado actual de los conocimientos humanos. La evolución. en efecto. ha podido y debido producir especies, tipos superiores a nuestra humanidad: no es probable que nosotros seamos el último peldaño de la vida, del pensamiento y del amor. ¿Quién sabe si la evolución no podrá o no ha podido hacer ya lo que los antiguos llamaban ediosess?

De esta manera puede ser conservado el fondo más puro del sentimiento religioso: la sociabilidad no sólo con todos los seres vivos y conocidos por la experiencia sino aún con los seres pensados y con los poderes superiores de que suponemos poblado el universo.

Asi formulado el sentimiento religioso debe ser llamado ultra-cientifico, pero nó anti-cientifico. Supone mucho sin duda al admitir una dirección posible de la evolución por seres llegados al grado superior; pero después de todo, como no podemos afirmar con certidumbre que esta dirección no exista o no haya de existir nunca, el sentimiento moral y social nos excita a obrar en nuestra esfera a fin de dar lugar. en cuanto dependa de nosotros, a esta dirección superior de la evolución universal.

Preocupa hondamente a Guyau el destino de la evolución de tener como término la disolución. $y$. en relación con este asunto, el problema de la inmortalidad del alma humana. Llega a fomar esta preocupación en nuestro filósofo proporciones angustiosas para caer después en la resignación estoica.

¿Cuál será el destino de ultra-tumba del hombre? se pregunta. La inmortalidad no está probada: pero tampoco está probado que no exista.

La creencia en una inmortalidad trascendente no puede entonces, según las expresiones de Fiske edefinirse más que de un modo negativo. como la resistencia a creer que este mundo sea todo. El materialismo sostiene que cuando hemos descrito el universo entero de los fenómenos, de que podemos tener conocimiento en las condiciones de la vida actual, todo se halla dicho. Me parece al contrario que todo no está dichos. Al menos agrega Guyau. es posible que todo no esté dicho. Pero para pasar de lo posible a lo probable serán menester siempre razones más positivas, sean de orden moral o de orden psicológico. Las especulaciones metafisicas por si solas dejarán siempre al espiritu ante un simple problema.

En general, siendo la idea de vida eterna por completo trascendente, no cabe formar sobre ella sino sueños más o menos misticos. Dejemos, pues. a un lado esta manera de buscar y acerquémonos a la naturaleza y a la experiencia. 
En lugar de hablar de eternidad hablemos de supervivencia y de una inmortalidad condicionada de hecho por las leyes mismas de la materia o del espíritu y a la cual, por lo demás todos pudiéramos llegar un día.

En este terreno podemos encontrar en primer lugar una especie de inmortalidad en lo que sobreviva de nuestras acciones buenas y de nuestros pensamientos. Es una manera de seguir viviendo en el corazón de los demás por el amor y el desinterés.

Pero una supervivencia de esta clase no es la vida personal de ultratumba con que sueñan los más de los hombres. La verdad que unos pocos sabios dirán que querer eternizar el individuo no es más que un resto de egoísmo: pero no es fácil conformarse con la extinción total de la vida y en sus esfuerzos desesperados por salvar de alguna manera la inmortalidad dice Guyau:

-No está probado que la inestabilidad sea el carácter definitivo y perpetuo de las funciones más elevadas de la conciencia. La esperanza filosófica (?) de la inmortalidad está fundada en la creencia opuesta, según la cual en el último grado de la evolución la lucha por la vida sería una lucha por la inmortalidad... La naturaleza vendría entonces, no a fuerza de simplicidad sino de complejidad sabia, a realizar una especie de inmortalidad progresiva, último producto de la selección. .

Esto si queréis es hermoso: pero ¿no es pura fantasia?

Ya hemos dicho que el proceso de la evolución lleva implicado consigo el de una disolución consiguiente. De esta suerte lo han pensado todos los filósolos desde Heráclito hasta Spencer. ¿Pero ha de ser fatalmente siempre así? se pregunta Guyau. ¿No podriamos concebir el advenimiento de seres dolados de una inteligencia superior, capaces de hallar los medios que impedirían la disolución?

Aqui vamos a encontrar a nuestro filósolo lanzado por último en una hermosa lucubración sobre una forma de la vida superior perdurable.

Además de la infinidad de los números y de la eternidad de los tiempos (con que podamos contar para concebir la aparición de una inteligencia como la indicada en el párrafo anterior) una nueva razón de esperanza es para Guyau la inmensidad misma de los espacios, que no nos permite juzgar el estado futuro del mundo únicamente por lo que pasa en nuestro sistema solar y aún estelar. ¿Somos nosotros acaso los únicos seres pensantes en el universo? Sin sobrepasar con mucho los datos ciertos de la ciencia se puede desde luego decir que no. Hay probablemente una infinidad de astros extinguidos y que han llegado poco más o menos al mismo punto de evolución que nuestra tierra; cada uno de estos astros ofrece una composición física y química sensiblemente análoga a la de nuestro planeta... La vida orgánica y consciente. leniendo condiciones aún más determinadas que las de la vida inorgánica, ha debido ser arrastrada en una evolución que, a pesar de toda la diferencia de los medios, habrá ofrecido sin duda muchas analogías con la de las especies animales y humanas en nuestra tierra.

Se puede, pues, sin que parezca demasiado inverosímil, admitir que existan una infinidad de humanidades análogas a la nuestra en sus facultades esenciales. 
Son nuestros hermanos planetarios. Talvez algunos de ellos son como dioses respecto de nosotros. Es lo que quedaría de verdadero de las antiguas concepciones que poblaban los cielos con seres divinos. $Y$ de aquí, así como un día por la comunicación más estrecha de las conciencias individuales podria establecerse en nuestra propia tierra una especie de conciencia humana, de igual manera se podria. sin que haya en ello nada de absurdo. soñar con que en lo infinito de las edades se realice una conciencia intercósmica... Dios es paciente porque es eterno, dicen los teólogos. La fuerza psíquica. ser pensante, el hombre. puede ser paciente porque en cuanto energía de la naturaleza es también eterna.

De esta perspectiva que abre el filósofo ante nosotros no tenemos que decir sino que la hallamos bella y grandiosa; y. mas aún, por fantástica que parezca. la hallamos también plausible.

La vida perdurable formulada en las lineas anteriores no salva sin embargo las individualidades. Si todos estos consuelos se muestran ineficaces, no queda. dice Guyau, por último. nada más que afrontar la muerte estoicamente y sno ser cobardes.

La actitud de Guyau ante el problema religioso en lo que tiene de incierta. de inquieta y casi de angustiosa, no es una novedad en nuestro tiempo. Ha sido la de muchas inteligencias superiores después del Renacimiento y sobre todo a contar desde el siglo XVIII. Han visto minados los dogmas del cristianismo por los progresos de la filosofia y de la ciencia. ellos mismos los han atacado con las armas aguzadas de la razón: pero no han podido dejar de ver también que un sentido absoluto de la vida rebalsa los limites de la ciencia, no han podido dejar de ver que ese sentido absoluto tiene que ser obra de alguna forma de le. O la vida se queda sin sentido.

Se halla en lo cierto Guyau al pensar que en esta trágica emergencia, deshechos los dogmas que se han ofrecido como interpretación infalible a la dócil mentalidad humana, los individuos deben ser los obreros de sus propias creencias. deben representarse a su manera el eferno enigma. Es lo que ha denominado nuestro filósolo la anomia religiosa. o sea el individualismo religioso. la falta de unidad de creencias.

- La religión. dice Boutroux, abundando más o menos en las mismas ideas. es la reivindicación. al lado del punto de vista de la ciencia. del punto de vista del sentimiento y de la fe. Para ella el valor de las libertades no se mide por la cantidad de conocimientos cientificos que hacen valer. La individualidad como tal. tanto la del ignorante como la del sabio. la del criminal como la del hombre honrado, tiene un valor propio. Un mundo en que reinan la personalidad. la libertad de equivocarse, la variedad y la armonia. es, para el hombre religioso. mejor, más bello. más análogo a la perfección divina que un mundo en que todo no fuera más que la aplicación mecánica de una fórmula única e inmutable. La sola manera para lo finito de imitar a lo infinito consiste en diversificarse hasta 
lo infinito. Por esto el hombre religioso aprecia en los otros hombres principalmente, no los puntos que se parecen a él. sino aquellos en que difieren de él. No solamente tolera estas diferencias. Ellas son, a su entender, piezas de la armonia universal: son el ser de los otros hombres, y. por esto mismo constituyen la condición del desarrollo de su propia personalidad.

En medio de esta hermosa diversidad lo que subsistirá de las diferentes religiones, según Guyau, serán las asociaciones de los que compartan las mismas concepciones hipotéticas. asociaciones levantadas sobre una base de libertad y mantenidas por las garantias de la tolerancia.

Y en esta busca afanosa y sincera de Dios. Dios falvez se irá haciendo, irá existiendo en los que lo realicen en su corazón. 